\title{
|!:
}

\section{O BRASIL QUE INTERSECCIONA, NORMATIZA E POSSUI “TONS DE PELE"}

\section{BRAZIL THAT INTERSECTIONS, NORMATIZES AND HAS "SKIN TONES"}

\author{
Ilrismar Oliveira dos Santos \\ Universidade Federal do Sul da Bahia (UFSB). E-mail: yuri-oliveira82@ hotmail.com
}

Artigo submetido em 05/03/2019, aceito em 15/06/2019 e publicado em 23/12/2019.

\begin{abstract}
Resumo: O presente estudo tem por finalidade discutir o Racismo, o Antirracismo e outros marcadores que contribuem para a segregação dos indivíduos. Para tanto, fez-se um levantamento bibliográfico dos materiais que contemplam a área das relações étnico-raciais e das interseccionalidades. $\mathrm{O}$ texto traz uma reflexão sobre a dicotomia raça/cor, associando-as ao que se entende por racismo e antirracismo brasileiro. Sendo assim, almeja-se, de início, trazer a ideia de como o país vem lidando com as questões raciais. A partir daí, abordar como os processos dos cruzamentos fenótipos, biótipos e identitários contribuem para traçar rótulos que classificam homens e mulheres em diferentes categorias das relações sociais. Por conseguinte, e não menos importante, trazer breves apontamentos acerca das legislações que coíbem as práticas de racismo. Assim, esse estudo elucida as concepções de raça/cor, racismo/antirracismo e interseccionalidades por um viés analítico, trazendo questões que versam sobre o racismo velado, o embranquecimento como fruto das relações inter-raciais e os marcadores que atravessam homens e mulheres em sua constituição identitária.
\end{abstract}

Palavras-chave: Racismo; embranquecimento; interseccionalidades; identidade.

\begin{abstract}
The present study aims to discuss Racism, Anti-Racism and other markers that contribute to the segregation of individuals. Therefore, a bibliographic survey of the materials that contemplate the area of ethnic-racial relations and intersectionalities was made. The text brings a reflection on the race / color dichotomy, associating them with what is meant by brazilian racism and anti-racism. Thus, it aims, at first, to bring the idea of how the country has been dealing with racial issues. From there, address how the processes of phenotype, biotype and identity crossings contribute to draw labels that classify men and women in different categories of social relations. Therefore, and not least, bring brief notes about the laws that curb the practices of racism. Thus, this study elucidates the conceptions of race / color, racism / anti-racism and intersectionalities by an analytical bias, bringing questions about veiled racism, whitening as a result of interracial relations and the markers that cross men and women in their identity constitution.
\end{abstract}

Keywords: Racism; whitening; intersectionalities; identity.

\section{INTRODUÇÃO}

O presente artigo foi elaborado a fim de discutir acerca do cenário racista que constituiu e ainda se faz presente na história da identidade do povo brasileiro, uma vez que as concepções de racismo e antirracismo transmutam na sociedade contemporânea, onde o primeiro é 
generificado e o segundo tomado como modelo para implementação de políticas públicas que ora segregam, ora oportunizam.

Diante disso, esse texto traz para discussão a dicotomia cor/raça no cenário nacional, reforçando a ideia de que os marcadores biológicos não são nítidos para a distinção das pessoas e de que a pauta do racismo no Brasil é tratada com um olhar melindroso pelas ações afirmativas. Então, esse texto objetiva colaborar no campo dessas discussões, auxiliando ou associando novos conceitos.

Vale salientar que os estudos sobre racismo e cor também se mesclam com outros elementos da formação social e humana, ou seja, existem marcadores que influenciam nas descrições do indivíduo. Portanto, a abordagem sobre o que intersecciona o sujeito é preponderante para que se identifique as características físicas e sociais que lhes atravessam, fomentando um distanciamento ou aproximação das oportunidades sociais.

Somado a isso, e em face das nítidas desigualdades no campo humano e socioeconômico, foram sancionadas leis que assegurassem, oportunizassem, trouxessem equidade e maiores garantias à população negra. Isso foi um avanço nas políticas raciais, porém faltam aplicabilidade e fiscalização dos normativos para que se cumpram com os direitos e garantias de homens e mulheres negras.

Para tanto, esse artigo foi elaborado com base em pesquisas bibliográficas que contemplassem a temática a fim de contradizer, afirmar ou adicionar novas informações ao vasto campo de pesquisa das relações étnico-raciais. Desse modo, trabalhos como o de Abdias do Nascimento (1978); Antônio Sérgio Alfredo Guimarães (1995 e 1999); Lia Vainer Schucman (2010); Raissa Rossi Trentini (2014), jornal online Correio e as leis $n^{\circ} 7.716 / 89$ e $n^{\circ}$ 9.459/97 se fizeram necessários para a construção desse texto científico.
Assim, o presente texto almeja contribuir para o campo das discussões étnico-raciais, pois constitui-se de elementos que favorecem o debate reflexivo acerca dos fenótipos e demais contextos que segregam homens e mulheres por conta da raça/cor. Portanto, esse material se edifica nessa dicotomia, uma vez que ainda há distorções de como esses marcadores se interseccionam e se postulam na identidade do povo brasileiro.

\section{PROCESSOS METODOLÓGICOS: MATERIAIS E MÉTODOS}

$\mathrm{O}$ interesse por buscar material científico para complementar e dar maior visibilidade a temática racial reside no fato de que o preconceito de classe, de gênero e de cor não cessaram dos espaços de convivência humana, mas se transformaram em atitudes e ações envoltas de meias-verdades, gentilezas disfarçadas de uma identidade nacional ímpar que se depara com uma política antirracista e nada preconceituosa. A sociedade está repleta de seres humanos bem-intencionados que sempre conseguem e se ajeitam na promoção dos rechaços de um para com o outro, pois tudo se transforma em um racismo velado.

Desse modo, esse trabalho reuniu material bibliográfico acerca da temática em questão e buscou por meio de resumos, fichamentos e sínteses lançar mão de conteúdos que pudessem ser contestados, complementados, ressignificados dentro do viés identitário e que se voltasse para a formação social e política do homem e da mulher negra.

Para a construção do presente texto, foi necessário a busca em sites e livros acerca da temática do racismo, antirracismo e construção da identidade nacional, posteriormente ocorreram leituras que conduziram a produção de pequenos textos e fichamentos bibliográficos. Em seguida, em posse dos resumos, houve a construção do texto final. 


\section{RESULTADOS E DISCUSSÃO}

Antes de qualquer discurso é preciso entender o porquê da segregação racial nos espaços humanos, ou seja, o que desencadeou as distinções entre as pessoas. Para Schucman (2010) "o racismo é mais especificamente entendido como uma construção ideológica, que começa a se esboçar partir do século XVI com a sistematização de ideias e valores construídos pela civilização europeia".

Desse modo, o termo teve origem com o domínio europeu sobre as civilizações abastadas de um pensamento crítico sobre as relações sociais. O racismo então surgiu como uma necessidade de explicar a supremacia dos brancos sobre as populações colonizadas, as quis carregavam uma cor que não coincidia com os traços de civilidade humana.

De acordo com Guimarães (1999) o racismo se fundamenta dento das limitações e subserviência de um povo sobre o outro:

Dentre as formas de legitimação da subordinação de um povo ou de uma etnia, ou raça ou classe social estão: (a) o poder militar demonstrado pelos conquistadores; (b) o carisma racial, de cor ou étnico (justificativa biológica ou cultural); (c) o desempenho socioeconômico e cultural dos indivíduos (a pobreza e sujeição como "prova" de inferioridade). (GUIMARÃES, 1999, p. 110)

Tomando o Brasil como exemplo, é nítido que a exploração cultural e econômica foram $\mathrm{o}$ ápice para $\mathrm{o}$ fortalecimento do pensamento racista. Em verdade, sempre existiram correntes opressoras responsáveis pela segregação de homens e mulheres de cor fazendo com que esses se curvassem diante dos arianos e de seus ideais etnocêntricos. "Em geral, o racismo brasileiro, quando publicamente expresso, o é por meio de um discurso sobre a inferioridade cultural dos povos africanos e o baixo nível cultural das suas tradições e de seus descendentes (GUIMARÃES, 1999, p. 109).

Schucman (2010) traz o seguinte pensamento:

O racismo, portanto, serviu nesse momento para que os Estados-Nações exercessem um poder contra sua própria população, pois a ideia de purificação permanente da população torna-se uma das dimensões essenciais da normalização social. Essa visão constitui uma tomada de poder sobre a vida humana, onde os discursos biólogos e médicos ganham extrema importância, conduzindo a uma estatização do biológico. Assim, as tecnologias de poder que têm como principal objetivo a manutenção da vida também são aquelas que exercem o direito de matar - segregacionar -, excluir os indivíduos dentro da própria sociedade. (SCHUCMAN, 2010, p.44)

Evidencia-se que, teoricamente, o Brasil nunca passou por uma segregação racial tão explícita como os Estados Unidos. Há, portanto, uma máscara nacional de proporções histórica e metafórica que encobriu todos os passos do preconceito imputado pela cultura branca e hegemônica. Construiu-se uma imagem pacífica entre os negros e os brancos após o período de escravidão, ou seja, viveram harmonicamente a sem incitação de conflitos ou provocações culturais que chegassem às nações vizinhas.

"Essa pretensão a um antirracismo institucional tem raízes profundas tanto na nossa história, quanto na nossa literatura" (GUIMARÃES, 1995, p. 26). A imagem de nação civilizada e que não dissociava os indivíduos por meio da cor causou rechaços silenciosos. Ainda para Guimarães (1995, p. 27) "a linguagem de classe e de cor no Brasil sempre foi usada de modo racializado". Isso traz uma generalização do que é o racismo no país, ou seja, ele se vincula a todos os aspectos que diminuem, que evidenciam o tom de pele, as escolhas, as preferências e a posição social do outro. 
Guimarães (1999) elenca o que seria o racismo contemporâneo:

Em primeiro lugar, qualquer explicação ou justificativa para diferenças, preferências, privilégios e desigualdades entre seres humanos baseada na idéia de raça pode, em princípio, ser considerada racista, posto que não há base científica que possa sustentar que o que chamamos de "raças" tenham qualquer realidade metasocial ou física [...]

Racismo pode, ademais, referir-se não apenas a doutrinas, mas a atitudes (tratar diferencialmente as pessoas de diferentes raças e culturas, ou seja, discriminar) e a preferências (hierarquizar gostos e valores estéticos de acordo com a idéia de raça ou de cultura, de modo a inferiorizar sistematicamente características fenotípicas raciais ou características culturais) [...]

Em terceiro lugar, pode-se precisar melhor o racismo, tal como se manifesta, por suas consequências e dizer que a manutenção e reprodução de desigualdades sociais e econômicas, por meio dos mais diferentes mecanismos, entre grupos de pessoas identificadas como de diferentes raças, etnias ou cores constituem racismo desde que operem mecanismos de discriminação que possam ser retraçados à idéia de raça [...]

Em quarto lugar, podemos ainda definir o racismo não com referência a atitudes, ações e preferências individuais, mas com relação a um determinado sistema social. (GUIMARÃES, 1999, p. 105)

Comparando esse cenário com o período da servidão permissiva, verifica-se que o racismo transmutou da legalidade do acoite para a coação camuflada por sutilezas. Então, com a modernidade a supremacia branca necessitou ocultar seus rechaços para burlar os novos discursos de liberdade e fraternidade, ou seja, receber novas adaptações para contrapor os lugares de fala tendenciosos e envoltos por pensamentos de equidade política.

Porém, antes dessa preocupação moral, há séculos os defensores da raça ariana buscavam alternativas que deixassem o mais branco possível o biótipo do homem e da mulher brasileira, ou seja, já se pensava no processo de branqueamento. Desse modo, uma parcela da população visando o bem-estar nacional já arquitetavam estratégias que clareassem o povo brasileiro por meio das relações inter-raciais.

Nesse tocante, Nascimento (1978) diz que:

Para a solução dêste grande problema- a ameaça da "mancha negra" -já vimos que um dos recursos utilizados foi o estupro da mulher negra pelos brancos da sociedade dominante, originando os produtos de sangue misto: o mulato, o pardo, o moreno, o pardavasco, o homem-decôr, o fusco [...] O crime de violação cometido contra a mulher negra pelo homem branco continuou como prática normal através das gerações. (NASCIMENTO, 1978, p. 69)

Porém, nenhuma vantagem ou ascensão cultural foi sentida a ponto de dar notoriedade a essa nova raça, pelo contrário, "o processo de mulatização, apoiado na exploração sexual da negra, retrata um fenômeno de puro e simples genocídio" (NASCIMENTO, 1978, p.69). Tal acontecimento acarretou em contentamento pela elite branca, pois o embranquecimento demostrava o poder cromático de uma biologia sobre outra, ou seja, o mais forte estava vencendo. É preciso reforçar que "durante os tempos da escravidão, esta política de embranquecer a população estruturava-se de forma a limitar de qualquer maneira o crescimento da população negra". (NASCIMENTO, 1978, p. 70)

Para Schucman (2010, p. 44) "Considero racismo qualquer fenômeno que justifique as diferenças, preferências, privilégios, dominação, hierarquias e desigualdades materiais e simbólicas entre seres humanos, baseado na ideia de raça". Portanto, o racismo se instituiu e se molda naquilo que retira direitos com base na 
seleção de indivíduos mais capacitados e mais qualificados que outros.

Fazendo um paralelo com o comportamento segregacionista dos Estados Unidos que minimizavam, separavam e formavam grupos raciais com a política racista brasileira, nota-se "um sistema muito complexo e ambíguo de diferenciação racial, baseado principalmente em diferenças fenotípicas e cristalizado num vocabulário cromático" (GUIMARÃES, 1995, p. 28).

Seguindo com a análise dos apontamentos de Antônio Sérgio Alfredo Guimarães evidenciados em seu artigo Racismo e Antirracismo no Brasil (1995):

A análise do campo discursivo do racismo, tanto antigo (biologismo), quanto novo (diferencialismo cultural), introduziu a percepção de que, ao analisarmos hierarquias, estávamos lidando com um mesmo processo sub-reptício de "naturalização" e com formas diversas de essencialismo que se escondiam sob diferentes fenômenos empíricos. (GUIMARÃES, 1995, p. 30)

Esse apontamento traz a reflexão de que tanto os marcadores fenótipos quanto os culturais quando vistos de um plano hierárquico reproduzem um discurso que dificulta a distinção entre o racismo e as demais formas de rechaços produzidos, ou seja, qualquer forma de diminuição do outro pode ser classificada como uma ação racista.

Diante disso, o termo racismo foi e ainda é imputado a qualquer tipo de preconceito de cor, de classe, de vocábulos e de locais de fala não bem aceitos. Todavia, "chamar de racismo qualquer construção de discriminação baseada em construção essencialista, significava transformar o racismo numa simples metáfora, numa imagem política". (GUIMARÃES, 1995, p. 31). Desse modo, o racismo é responsável por explicar o nível social e cultural do indivíduo, sendo então sinônimo do que é inferior.
Ainda analisando o trabalho de Guimarães (1995):

A ordem econômica, por exemplo, pode ser justificada como sendo um produto de virtudes individuais (os pobres são pobres porque lhes faltam sentimentos nobres, virtudes e valores do ethos capitalista); do mesmo modo, se justifica usualmente a posição subordinada das mulheres pelas características do sexo feminino; a escravidão dos africanos, assim como a posição social inferior de seus descendentes, pelas limitações da "raça" negra etc. (GUIMARÃES, 1995, p. 31)

Então, a miséria, a exclusão e toda forma de segregação de cor, de gênero, de classe são simplesmente resumidos em um termo genérico e que pode explicar os processos que recaem sobre o outro. Até aqui, compreendeu-se que o racismo brasileiro estabelece conexões com todas as minorias e que os critérios para categorizar o que seria ou não uma prática racista se confunde no próprio campo das raças. Indo nas categorizações do racismo, Guimarães (1999) diz que:

Em geral, o racismo brasileiro, quando publicamente expresso, o é por meio de um discurso sobre a inferioridade cultural dos povos africanos e o baixo nível cultural das suas tradições e de seus descendentes. Grosso modo, tal racismo atravessou duas grandes fases: a da discriminação racial aberta, mas informal e secundada pela discriminação de classe e de sexo, que gerava uma segregação de fato dos espaços públicos e privados (praças e ruas, clubes sociais, bares e restaurantes etc.); e a fase atual, quando, com a discriminação e a segregação raciais sob fogo, apenas os mecanismos estritos de mercado (discriminação de indivíduos e não de grupos) ou psicológicos de inferiorização de características individuais (ou autodiscriminação) permitem a reprodução das desigualdades raciais. (GUIMARÃES, 1999, p.109) 
Como já fora mencionado, o racismo ganha outras dimensões, não sendo restrito aos processos raciais. Esse aspecto dimensiona toda ação discriminatória. A exemplo disso, o jornal eletrônico Correio trouxe uma matéria onde dizia que o Supremo Tribunal Federal $^{1}$, doravante STF, em 13 de junho de 2019 inseriu na pauta do racismo, até que se criasse uma lei específica, os crimes de homofobia, resguardando os direitos da população de Lésbicas, Gays, Bissexuais, Travestis e afins.

Tal ação foi um avanço nos direitos constitucionais e fundamentais para os cidadãos no Brasil, mas implementado nas leis de racismo. Deve-se elucidar que não há "uma regra clara de descendência biológica definindo grupos raciais, mas, ao contrário, as classificações seguem diferenças de aparência física [...]" (GUIMARÃES, 1995, p. 33). Existe no país uma seleção de indivíduos pertencentes aos diversos tons de pele, e não a grupos raciais definidos, ou seja, as pessoas são selecionadas mediante os traços físicos, dificilmente há uma classificação no tocante da ancestralidade.

Tendo então nos aspectos físicos dos indivíduos e suas condições socioeconômicas listados, os conceitos para a definição da raça (cor) estão prontos para a dissociação das classes. "É justamente desse modo que a cor no Brasil funciona como uma imagem figurada da raça [...] esses traços funcionam como critérios e marcas classificatórios". (GUIMARÃES, 1995, p. 33-34). Portanto, a cor apresenta algum significado quando se insere em algum grupo, mas que dentro dele haja traços que conduzam a alguma representatividade histórico/social. Esses apontamentos levam a conclusão de que a mestiçagem acabou por construir uma

1 CORREIO24HORAS. Por 8 votos a 3, STF criminaliza homofobia e transfobia. Disponível em: $<$ https://www.correio24horas.com.br/noticia/nid/po r-8-votos-a-3-stf-criminaliza-homofobia-etransfobia/>. Acesso em 15 de jun. 2019. fraqueza na luta pelo empoderamento negro. Acerca disso Guimarães (1995) aborda que:

Consequentemente, no Brasil,
somente aqueles com pele realmente
escura sofrem inteiramente a
discriminação e o preconceito antes
reservados ao negro africano.
Aqueles que apresentam graus
variados de mestiçagem podem
usufruir, de acordo com seu grau de
brancura (tanto cromática quanto
cultural, dado que "branco" é um
símbolo de "europeidade"), alguns
dos privilégios reservados aos
brancos. (GUIMARÃES, 1995, p. 36)

Quando se fala em privilégio voltados a nova coloração da pele, cria-se um estereótipo de que a ascensão social de um indivíduo se atrela, primeiramente, a sorte por ter nascido branco/caucasiano. Essa situação condiz com o desejo de instaurar no país uma sociedade branca, patriarcal e hegemônica.

Para Nascimento (1976):

\begin{abstract}
Uma afirmação exemplar emitida pela ideologia racial brasileira: a assunção de que as pessoas de origem índia ou africana preferem ser rotuladas de brancas e a simultânea presunção de que a benevolência da estrutura social em lhes concedendo o privilégio do status de "branco" constitui prova da ausência de preconceito ou discriminação racial! (NASCIMENTO, 1976, p. 76)
\end{abstract}

Esse aspecto denota uma cultura racista, pacificamente aceita e apropriada pelo próprio rechaçado. Ao abordar sobre a miscigenação, vai-se de encontro as vastas migrações e imigrações ocorridas no pais, onde algumas regiões foram mais propensas a esse processo que outras, e isso desencadeou outras multiplicidades de rechaços. De acordo com Guimarães (1995):

De qualquer modo, o fato é que as comunidades étnicas formadas por imigrantes e seus descendentes, vistas pelos brasileiros de quatro costados 
como "estrangeiros" — e que viam desdenhosamente os "brasileiros" —, essas comunidades, uma vez absorvidas às "elites" sulistas ou às classes médias nacionais, passaram a redefinir os outros, principalmente às classes trabalhadoras e à "ralé" brasileira tradicional, marcadamente mestiça, como "baianos", "paraíbas", ou "nordestinos" (GUIMARÃES, 1995, p. 43).

O Brasil que se mostrava cordial com os estrangeiros, em sua formação, diminuía seu povo e sua cultura. O que, de fato, não mudou na contemporaneidade. Vale ressaltar que a formação do povo brasileiros envolve uma multiplicidade de identidades e fenótipos, esses que influenciaram diretamente na concepção de cor, produzindo um entrelaçamento racial. No mais, toda construção histórica brasileira foi marcada por elementos que se cruzaram.

Com efeito, a interseccionalidade é um conjunto de marcadores sociais que se cruzam e culminam na constituição das identidades, das raças - cores -, do gênero e dos aspectos socioeconômicos das pessoas. Esses cruzamentos, por vezes, incidem em maiores ou menores graus de preconceito. Para melhor definir, toma-se como exemplo uma mulher negra, periférica e lésbica que busca por espaços em uma sociedade racista, elitista e heteronormativa. Essa terá dificuldades na interação com alguns grupos por conta do seu fenótipo, de sua posição socioeconômica e de sua orientação sexual que fogem às estruturas da normalização.

Entende-se que a formação da identidade do povo brasileiro se fez por um caminho de intersecções, ou seja, por situações que se cruzaram, pela mestiçagem e pelas múltiplas culturas. Aqui foi exemplificado uma situação que suprime determinados espaços políticos de uma mulher por assumir outros marcadores. Essa situação lembra que a ancestralidade, esquecida por conta de inúmeros casamentos inter-raciais, passou por fortes intersecções até perder seus aspectos raciais.

Compreende-se, portanto, que a interseccionalidade é uma aliada para a implementação de políticas de redistribuição e/ou políticas públicas que tenham como base a ressignificação das questões raciais, pois todas essas se interseccionam em sua própria constituição, ou seja, as questões étnicas envolvem subquestões sociais e históricas.

Então, abordar sobre os marcadores sociais que são responsáveis pela composição identitária é algo que se faz a fim de melhor entender a si e ao outro, mas há uma política de rotulação ao definir ou ser definido, todavia, é preciso se reconhecer, identificar para ressignificar. Diante disso, o que constitui o outro não deve ser entendido como meras escolhas ou tendências que perpassam a personalidade, mas sim, o ser em sua totalidade.

Tudo isso fora explicado para concluir que a sociedade foi constituída de marcadores que segregam dentro de todo e qualquer espaço das relações humanas. Partindo disso, a interseccionalidade deve ser entendida como mecanismo que constitui o ser e não como produto de rechaços.

A partir dos textos e das considerações supracitadas, vale trazer para esse artigo uma breve análise das leis $\mathrm{n}^{\circ} 7.716 / 89$ e $\mathrm{n}^{\circ}$ 9.459/97 e suas devidas alterações. A primeira teve origem com o objetivo de punir os indivíduos que cometessem preconceitos de raça ou cor e já deixava isso claro em seu primeiro artigo. A saber, "Art. $1^{\circ}$ Serão punidos, na forma desta Lei, os crimes resultantes de preconceitos de raça ou de cor". (BRASIL, 1989).

Já a lei $n^{\circ}$ 9.459/97 modificou dois artigos da lei anterior e acrescenta parágrafo. Assim, “altera os arts. $1^{\circ}$ e 20 da Lei $\mathrm{n}^{\circ} 7.716$, de 5 de janeiro de 1989 , que define os crimes resultantes de preconceito de raça ou de cor, e acrescenta parágrafo 
ao art. 140 do Decreto-lei ${ }^{\circ} 2.848$, de 7 de dezembro de 1940" (BRASIL, 1997).

"Art. $1^{\circ}$ Serão punidos, na forma desta Lei, os crimes resultantes de discriminação ou preconceito de raça, cor, etnia, religião ou procedência nacional."

"Art. 20. Praticar, induzir ou incitar a discriminação ou preconceito de raça, cor, etnia, religião ou procedência nacional.

Art. $2^{\circ} \mathrm{O}$ art. 140 do Código Penal fica acrescido do seguinte parágrafo:

"Art. 140.

$\S 3^{\circ}$ Se a injúria consiste na utilização de elementos referentes a raça, cor, etnia, religião ou origem:

Pena: reclusão de um a três anos e multa." (BRASIL, 1997).

No primeiro parágrafo do novo texto são adicionadas palavras como discriminação, preconceito de raça, cor, etnia, religião ou procedência nacional. O que traz maiores possibilidades de abarcar as múltiplas segregações que são acometidas contra a população negra. Por conseguinte, os falares ou atitudes que inibiam, diminuíam as pessoas em face de sua raça, cor, etnia, sincretismo religioso e origem nacional passara a ter maior proteção legal.

Salienta-se que os normativos não serão discutidos com profundidade, uma vez que isso demandaria outra linha de pesquisa, todavia serão elencados os elementos essenciais que fomentaram sua elaboração, pois deve ficar evidenciado que os direitos e garantias da população negra foram traçados por existir no país um histórico de rechaços e diminuição dos valores da população negra.

Essa legislação, em suma, versa sobre os impedimentos e as restrições da população negra nos espaços sociais, portanto chega-se ao entendimento de que foi preciso criar normativos para fazer com que a população branca entendesse os reais direitos de liberdade dos negros em território nacional, o que denota uma falsa política de gentilezas e afirmação de que há equidade nas prerrogativas legais.

Para tanto o texto da lei, por vezes, se perde na sociedade brasileira que ainda segue o ranço do embranquecimento europeu. Há inúmeros rechaços que são ocultados e, até mesmo, expostos por falares esdrúxulos que se fortalecem com outros discursos de ódio embasados na inverdade dos privilégios recebidos pela população negra. Esse entendimento errôneo leva a importância de se pontuar breves conceitos que diferenciam injúria racial de racismo.

De acordo com Trentini (2014):
A injúria preconceituosa é conceituada pela doutrina como sendo um crime contra a honra, ocasionado em relação a uma pessoa específica, embora valendo-se de instrumentos relacionados a um grupo de pessoas; diferente é o crime de racismo, o qual é direcionado à ofensa de um grupo de pessoas e não somente a um indivíduo (TRENTINI, 2014, p. 12).

As colocações da autora são assim entendidas: uma pessoa que se sinta pressionada em realizar alguma tarefa ou que se veja diminuída em uma situação por conta de seus traços biológicos sofre injúria; já o racismo se constitui em ofensas voltadas a determinados grupos ou coletivos étnico-raciais.

No que concerne ao direito de frequentar, usufruir e ter atendimento nos diferentes espaços públicos e privados, a lei $n^{\circ} 7.716 / 89$ traz do artigo $7^{\circ}$ ao $14^{\circ}$ um texto carregado de uma semântica negativa que lembra um passado repleto de restrições. A saber:

Art. $7^{\circ}$ Impedir o acesso ou recusar hospedagem em hotel, pensão, estalagem, ou qualquer estabelecimento similar.

Pena: reclusão de três a cinco anos. Art. $8^{\circ}$ Impedir o acesso ou recusar atendimento em restaurantes, bares, confeitarias, ou locais semelhantes abertos ao público.

Pena: reclusão de um a três anos. 
Art. $9^{\circ}$ Impedir o acesso ou recusar atendimento em estabelecimentos esportivos, casas de diversões, ou clubes sociais abertos ao público.

Pena: reclusão de um a três anos.

Art. 10. Impedir o acesso ou recusar atendimento em salões de cabeleireiros, barbearias, termas ou casas de massagem ou estabelecimento com as mesmas finalidades.

Pena: reclusão de um a três anos.

Art. 11. Impedir o acesso às entradas sociais em edifícios públicos ou residenciais e elevadores ou escada de acesso aos mesmos:

Pena: reclusão de um a três anos.

Art. 12. Impedir o acesso ou uso de transportes públicos, como aviões, navios barcas, barcos, ônibus, trens, metrô ou qualquer outro meio de transporte concedido.

Pena: reclusão de um a três anos.

Art. 13. Impedir ou obstar o acesso de alguém ao serviço em qualquer ramo das Forças Armadas.

Pena: reclusão de dois a quatro anos.

Art. 14. Impedir ou obstar, por qualquer meio ou forma, o casamento ou convivência familiar e social (BRASIL, 1989).

Desse modo, a utilização do verbo impedir, traz linhas gigantescas de uma história voltada para a supremacia branca e capitalista que galgou durante séculos um crescimento econômico e de prestígio em face do sofrimento das populações africanas, mestiças e indígenas. Todavia, esse marcador lexical não despareceu de todo da sociedade brasileira, ele surge sem tanta timidez em alguns locais de fala.

Partindo para o cotidiano, isso não quer dizer que a mulher e o homem negro que diariamente vão à procura de emprego, que conduzem seu uber no trânsito caótico, que esperam o carro no estacionamento e que necessitam de visibilidade na carreira terão seus direitos de ir, vir e frequentar os espaços públicos e privados estejam assegurados pelos normativo, pois é necessário mais do que isso para mudar o quadro de racismo existente no Brasil, é fundamental que as discussões se iniciem nas escolas com um currículo que elenque, de fato, as contribuições da população negra para a construção da identidade nacional.

Ao sancionar leis ratificando os direitos e as garantias da população negra, o país lança seu pedido de desculpas, mas esse se faz por meio de uma semântica dissimulada do que fora e ainda é a população brasileira: racista e criadora de um antirracismo disfarçado de meras sutilezas.

\section{CONCLUSÕES}

A julgar pelo modo como as terras brasileiras foram colonizadas, é fácil chegar a conclusão do porquê da existência de uma política racista, que se mascara em um antirracismo ideológico. É fundamental mostrar aos vizinhos que não há confusão em casa; que há plena harmonia nos cômodos e nas pessoas que transitam no ambiente; que as visitas podem chegar, sentar-se à mesma e tomar um café sem maiores contratempos.

Esse exemplo, que mais se assemelha ao início de um conto, serve para explicar que o Brasil não adotou uma política de separação racial como nos Estados Unidos. Aqui, adotou-se o embranquecimento como última alternativa de salvação da identidade nacional, calcada na cultura eurocêntrica.

Foi evidenciado que o racismo não é unicamente uma questão de cor, mas de valores construídos em uma sociedade que se alimenta de um ranço patriarcal e com síndrome de raça ariana. Atualmente, o preconceito é vívido e se alimenta de estigmas criados no mercado de trabalho, na fila do supermercado, no trânsito, nas escolas e em todo e qualquer espaço em que haja uma maneira de um ser humano inferiorizar o outro.

No que concerne às leis e as ações afirmativas, as medidas empregadas para coibir o preconceito só reforçam que o país precisa evoluir no campo das relações étnico-raciais, pois quando a população de 
um país nega sua identidade ou inferioriza suas raízes por conta de uma tabela ilusória de cores é chegado o momento de ressignificar o processo identitário.

Chega-se ao entendimento de que o racismo ganhou corpo após o período de escravidão e, com os negros vivendo à margem da sociedade, fora fácil criar elementos que lhes trouxessem uma imagem degradante e imersas em rótulos animalescos de pobreza e ignorância. Já o antirracismo é fruto de uma política de igualdade condicionada ao exibicionismo pátrio, e que, até o momento, não obteve resultados significativos nas ações afirmativas.

\section{REFERÊNCIAS}

BRASIL. Decreto-lei $n^{\circ} \mathbf{2 . 8 4 8}$, de 7 de dezembro de 1940. Código penal. Disponível

em: <http://www.planalto.gov.br/ccivil_03/ decreto-lei/del2848.htm $>$.

BRASIL. Lei $\mathbf{n}^{\circ} \mathbf{7 . 7 1 6 / 8 9}$, de 5 de janeiro de 1989. Define os crimes resultantes de preconceito de raça ou de cor. Disponível em:

http://www.planalto.gov.br/ccivil_03/leis/l 7716.htm>.

BRASIL. Lei $n^{0}$ 9.459/97, de 13 de maio de 1997. Altera os arts. $1^{\circ}$ e 20 da Lei $n^{\circ}$ 7.716 , de 5 de janeiro de 1989 , que define os crimes resultantes de preconceito de raça ou de cor, e acrescenta parágrafo ao art. 140 do Decreto-lei $\mathrm{n}^{\circ} 2.848$, de 7 de dezembro de 1940. Disponível em: < http://www.planalto.gov.br/ccivil_03/leis/L 9459.htm>.

CORREIO24HORAS. Por 8 votos a 3, STF criminaliza homofobia e transfobia. Disponível em: <https://www.correio24horas.com.br/notici a/nid/por-8-votos-a-3-stf-criminalizahomofobia-e-transfobia/>. Acesso em 15 de jun. 2019.
GUIMARÃES. A. S. A. Racismo e Antirracismo no Brasil. Brown Universityn, no.43. p. 26-44, nov., 1995.

GUimarães. A. S. A. Combatendo o Racismo: Brasil, África do Sul e Estados Unidos. Revista Brasileira de Ciências Sociais, v. 14. no. 39. p 103 - 117, fev., 1999.

NASCIMENTO, A. D. O genocídio do negro brasileiro: Processo de um racismo mascarado. Rio de Janeiro: Editora Paz e Terra S/A, 1978.

SCHUCMAN. L. V. Racismo e Antirracismo: a categoria raça em questão. Psicologia política, v. 10. no. 19. p. 41-55. jan - jun. 2010.

TRENTINI, R. R. A (in) Aplicabilidade da Legislação Antirracista. 2014. 89f. Dissertação de Graduação na área de Direito - Centro Universitário UNIVATES, Lajeado, 2014. 